\title{
Point-of-care coagulometry in prehospital emergency patients - are international normalized ratios useful?
}

\author{
Manuel F. Struck ${ }^{1 *}$ and Peter Hilbert-Carius ${ }^{2}$
}

\section{Commentary}

With great interest we read the recent article of Beynon et al. [1]. The authors aimed to assess the validity of a point-of-care (POC) coagulometer measuring international normalized ratios (INR) utilized in a prehospital setting. Indeed, there is a great potential for POC tests in emergency patients and only few studies have been conducted. Although the authors highlighted limitations of their own study and the relevance of INR itself, we feel that the study has further important limitations seriously restricting the implications. Most important, the validity of a test is defined as the degree to which an instrument measures the construct it purports to measure, and this objective was not defined [2]. A coagulopathy in general does not exist and prothrombin times (PT) are not established tests for a coagulopathy in general. Since INR was developed only to monitor long-term treatment of vitamin K antagonists (VKA), effects of other coagulation conditions, i.e., antiplatelet treatment, thrombocytopenia, hyperfibrinolysis or inherited platelet disorders can not be detected by INR measurements. A possible application for POC coagulometers in the prehospital setting is to assess INR in emergency patients treated with VKA. However, this issue was extensively studied in large (non-emergency) cohorts involving appropriate sample sizes and valid study designs $[3,4]$.

In the past decades, VKA accounted for the most prescribed anticoagulants worldwide in patients with atrial fibrillation and deep vein thrombosis. This practice is now under considerable change since non-vitamin $\mathrm{K}$ antagonist oral anticoagulants (NOAC) are available [5]. The dimension of this change is currently not predictable but it might replace common practice patterns in the future. An interesting objective would be to observe

\footnotetext{
* Correspondence: manuelstruck@web.de

${ }^{1}$ Department of Anaesthesiology and Intensive Care Medicine, University

Hospital Leipzig, Liebigstr. 20, 04103 Leipzig, Germany

Full list of author information is available at the end of the article
}

the sensitivity of POC coagulometers for detecting these direct oral anticoagulants, i.e., rivaroxaban, apixaban, edoxaban or dabigatran [6]. Diagnosis of NOAC activity is not reflected by standard coagulation parameters (PT using INR or Quick's value, and partial thromboplastin time (PTT), respectively). Furthermore, patients under NOAC who sustain injuries and/or surgery are exposed to relevant risks of prolonged bleeding without abnormal standard coagulation parameters [6, 7]. This may potentially affect clinical practice in emergency medicine and attention of general practitioners.

We agree with the authors that the implementation of POC coagulometers might be feasible in pre-hospital emergency settings but the search for an easily available parameter enlightening the complexities of the entire coagulation system continues.

\begin{abstract}
Abbreviations
POC: Point-of-care; INR: International normalized ratio; VKA: Vitamin K antagonist; NOAC: Non-vitamin K oral anticoagulants; PT: Prothrombin time; PTT: Partial thromboplastin time.
\end{abstract}

\section{Competing interests}

The authors declare that they have no competing interests.

\section{Authors' contributions}

MFS wrote and drafted the manuscript. PH revised the manuscript. All authors read and approved the final manuscript.

\section{Acknowledgements}

We acknowledge support from the German Research Foundation (DFG) and University of Leipzig within the program of Open Access Publishing.

\section{Author details}

'Department of Anaesthesiology and Intensive Care Medicine, University Hospital Leipzig, Liebigstr. 20, 04103 Leipzig, Germany. ²Department of Anaesthesiology, Intensive Care and Emergency Medicine, Bergmannstrost Hospital, Halle, Germany.

\section{Received: 26 August 2015 Accepted: 12 November 2015} Published online: 19 February 2016

\section{References \\ 1. Beynon C, Erk AG, Potzy A, Mohr S, Popp E. Point of care coagulometry in prehospital emergency care: an observational study. Scand J Trauma Resusc Emerg Med. 2015;23:58.}

( Biomed Central

(c) 2016 Struck and Hilbert-Carius. Open Access This article is distributed under the terms of the Creative Commons Attribution 4.0 International License (http://creativecommons.org/licenses/by/4.0/), which permits unrestricted use, distribution, and reproduction in any medium, provided you give appropriate credit to the original author(s) and the source, provide a link to the Creative Commons license, and indicate if changes were made. The Creative Commons Public Domain Dedication waiver (http://creativecommons.org/publicdomain/zero/1.0/) applies to the data made available in this article, unless otherwise stated. 
2. Mokkink LB, Terwee CB, Patrick DL, Alonso J, Stratford PW, Knol DL, et al. The COSMIN study reached international consensus on taxonomy, terminology, and definitions of measurement properties for health-related patient-reported outcomes. J Clin Epidemiol. 2010;63(7):737-45.

3. Christensen TD, Larsen TB. Precision and accuracy of point-of-care testing coagulometers used for self-testing and self-management of oral anticoagulation therapy. J Thromb Haemost. 2012;10(2):251-60.

4. Nagler M, Raddatz-Muller P, Schmid P, Bachmann LM, Wuillemin WA. Accuracy of the point-of-care coagulometer CoaguChek XS in the hands of patients. J Thromb Haemost. 2013;11(1):197-9.

5. Barnes GD, Lucas E, Alexander GC, Goldberger ZD. National Trends in Ambulatory Oral Anticoagulant Use. Am J Med. 2015. doi: 10.1016/j.amjmed. 2015.05.044. [Epub ahead of print]

6. Ebner M, Peter A, Spencer C, Härtig F, Birschmann I, Kuhn J, et al. Point-ofCare Testing of Coagulation in Patients Treated With Non-Vitamin K Antagonist Oral Anticoagulants. Stroke. 2015;46:2741-7.

7. Weitz Jl, Pollack CV Jr. Practical management of bleeding in patients receiving non-vitamin $\mathrm{K}$ antagonist oral anticoagulants. Thromb Haemost. 2015;114(5). [Epub ahead of print].

\section{Submit your next manuscript to BioMed Central and take full advantage of:}

- Convenient online submission

- Thorough peer review

- No space constraints or color figure charges

- Immediate publication on acceptance

- Inclusion in PubMed, CAS, Scopus and Google Scholar

- Research which is freely available for redistribution 